Derleme Makalesi / Research Article

\title{
Veteriner İlaçlarının Çevrede Bulunuşu ve Etkileri
}

\author{
Ayșe ÖZGÜVEN* \\ Yüzüncü Yll Üniversitesi, Mühendislik Fakültesi, Çevre Mühendisliği Bölümü, Van \\ (ORCID:0000-0003-1071-2813)
}

\begin{abstract}
Özet
Veteriner ilaçları hastalığı tedavi etmek ve hayvan sağılığını korumak için yaygın olarak kullanılmaktadır. Hayvan hastalıklarının tedavisinde ve önlenmesinde kullanılan veteriner ilaçları, yoğun tarımsal ve su ürünleri yetiştiriciliğinden dolayı çevre kirliliğinin önemli bir kaynağını oluşturmaktadır. Hayvancılık ve tavukçuluk üretiminde kullanılan farmasötik maddeler hayvanlar tarafindan metabolize edildikten sonra dışkı yoluyla çevresel ortamlara bırakılırlar. Hayvan yemi ve kullanılmayan ilaçların uygunsuz bertarafı sonucunda yüzeysel su kaynaklarına kadar ulaşabilirler. Ayrıca hayvan gübrelerinin tarımsal alanlarda kullanılması veteriner ilaçlarının çevrede bulunmasına neden olmaktadır. Bu derlemede veteriner uygulamalarında yaygın olarak kullanılan ilaçların çevresel ortamlarda bulunuşu, davranışı, dönüşümü ve canlılar üzerindeki toksik etkileri hakkında mevcut bilgiler verilmektedir. Ayrıca düşük konsantrasyondaki ilaçların ve metabolitlerinin uzun vadeli etkileri, ekosistemdeki veteriner ilaçlarının davranışı ve çevresel etkileri araştırılmıştır.
\end{abstract}

Anahtar kelimeler: Çevresel etki, hayvancıllk, veteriner ilaçları.

\section{The Occurrence and Effect of Veterinary Pharmaceuticals in the Environment}

\begin{abstract}
Veterinary medicines are widely used to treat disease and protect animal health. Veterinary drugs used in the treatment and prevention of animal diseases constitute an important source of environmental pollution due to intensive agricultural and aquaculture. The pharmaceuticals used in livestock and poultry production are metabolized by animals and after that released into the environment by feces. They can reach to surface water resources as a result of inappropriate disposal of animal feed and unused medicines. In this review, current information on the presence, behavior, transformation and toxic effects of drugs in the environment commonly used in veterinary practices are given. In addition, the long-term effects of drugs and their metabolites on low concentrations, the behavior of veterinary drugs in the ecosystem and their effects on the environment were investigated.
\end{abstract}

Keywords: Environmental impact, animal husbandry, veterinary pharmaceuticals

\section{Giriş}

Hayvanlardaki hastalıkların tedavisinde ve önlenmesinde kullanılan veteriner ilaçları, yoğun tarım ve su ürünleri üretimi nedeniyle önemli çevre kirliliği kaynaklarını oluşturmaktadır. Veteriner ilaçları, İngiltere'de ve Avrupa'da hayvanların sağlığını korumak ve hastalıklarını tedavi etmek için yaygın olarak kullanılmaktadır. Büyümeyi destekleyici yem katkı maddeleri büyüme hızlarını arttırmak amacıyla besi amaçlı yetiştirilen hayvan yemlerine eklenmektedir. Bu bileşikler hayvanlar tarafindan tamamen metabolize edilememekte, büyük bir kısmı dışkı ve idrarla değişmeden atılmaktadır. Veteriner ilaçlarının çevrede bulunuşu ya doğrudan, örneğin balık çiftliklerinde ilaç kullanımı, ya da dolaylı olarak hayvan gübresinin toprağa uygulanmasıyla gerçekleşmektedir [1].Veteriner ilaçlarının kullanımından kaynaklanan çevresel risklerin daha iyi anlaşılması için Çevre Ajansı çeşitli çalışmalar yapmıştır. Bu kapsamda, maruz kalma yolları, çevresel akibet ve veteriner ilaçlarının tüm genel gruplarının etkileri hakkındaki mevcut verileri değerlendirmişlerdir. Birkaç veteriner ilaç grubunun (yani koyun

*Sorumlu yazar: ayseozguven@yyu.edu.tr

Geliş Tarihi: 28.03.2019, Kabul Tarihi: 23.09.2019 
banyolarında kullanılan kimyasallar, balık çiftliği ilaçları ve antelmintikler) çevrede bulunuşu ve etkileri nedeniyle çevresel olarak endişe verici olduğu bilinmektedir. Antibakteriyel maddeler, koyun banyolarında kullanılan kimyasallar ve reçeteli ilaçlar dâhil olmak üzere birçok veteriner ilaçlarının kullanımıyla ilgili çeşitli kaynaklardan elde edilen veriler mevcuttur [2]. Elde edilen verilere dayanarak, antibakteriyeller en yüksek miktarlarda satılmakta ve bunu koksidiostatlar, organofosforlu koyun banyolarında kullanılan kimyasallar, büyüme destekleyicileri, endoparazit koruyucular, genel anestezikler, ektoparazitik öldürücüler, antifungal maddeler, steroid olmayan antienflamatuar ilaçlar (NSAID'ler), hormonlar ve enterik preparatlar takip etmektedir [3]. Veterinerlik uygulamalarında çoğunlukla antibiyotikler, antiparaziter ilaçlar ve steroidal hormonlar kullanılır. Bir veteriner ilacın çevrede bulunma potansiyeli, tedavi tipi dâhil olmak üzere tedavi edilen hayvanların sayısı, metabolizma derecesi ve toprağa uygulamadan önce gübredeki bozunma gibi çeşitli faktörlere bağlıdır. Su ürünü yetiştiriciliğinde kullanılan ilaçlar, genellikle doğrudan çevreye verildiğinden sucul ortamlara ulaşma potansiyeli yüksektir, karasal ortama giriş yolu ise çiftlik hayvanlarının yetiştiriciliğinde kullanılan veteriner ilaçlarının kullanımından olacaktır. Şekil 1'de çevredeki veteriner ilaçlarının kaynakları gösterilmektedir [4].

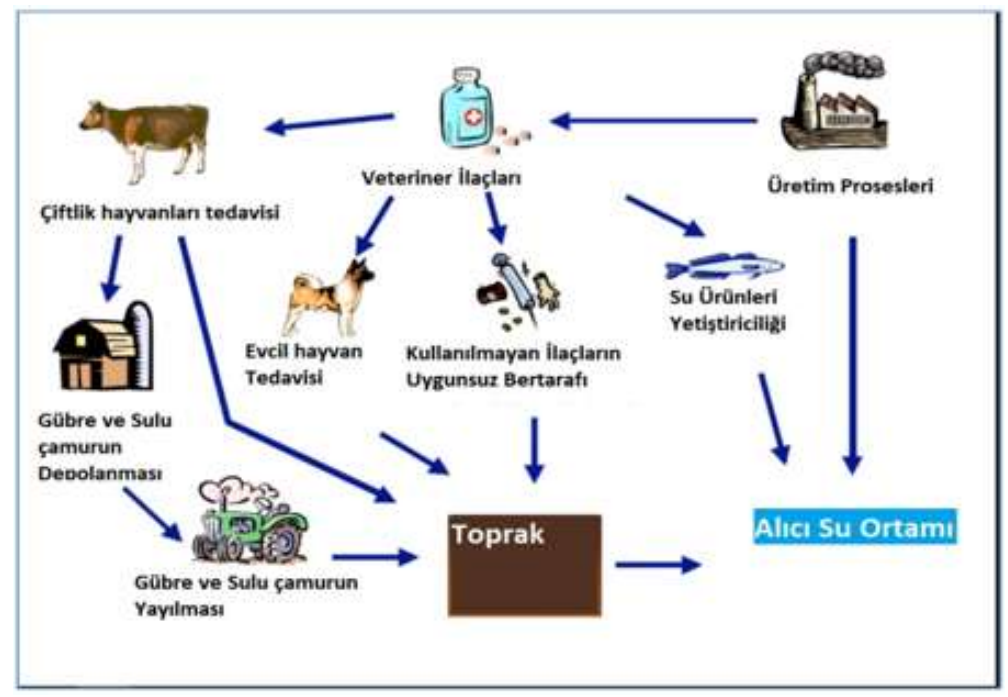

Şekil 1. Çevredeki veteriner ilaçlarının kaynakları

Bir veteriner ilacın çevre üzerindeki potansiyel etkisi aşağıda belirtilen bir dizi faktörle belirlenecektir:

-Kullanılan miktar ve kullanım modeli

-Metabolizma

-Gübre ve gübre çamurundaki kalıcılık

- Çevresel ortamlarda kalıcilik ve sorpsiyon

•Ekotoksisite

\section{Veteriner İlaçlarının Çevrede Bulunuşu}

Veteriner ilaçlarının çevreye girişinde başlıca yollar, çiftlik hayvanlarının tedavisi ve su ürünleri yetiştiriciliği tesislerinden kaynaklanmaktadır. Veteriner ilaçları genellikle yüzey suları, yeraltı suları, sedimentler, gübre ve biyotada tespit edilmiştir. İlaçların çevreye girişinin ana yolunu aktif farmasötik bileşenin kaplama, harmanlama, tablet sıkıştırma prosesleri sırasında imalat ekipmanlarının temizliğinde üretilen proses atıksuları oluşturmaktadır [5]. Veteriner ilaç ürünlerinin üretimi veya formülasyonu sırasında ortaya çıkan ve çevreye verilen zararların asgari düzeyde olması muhtemeldir. Boş konteynerlerin ve istenmeyen ürünlerin operatörler tarafindan uygun olmayan şekilde imha edilmesi, toprak ve suların kirlenmesine neden olabilir. İstenmeyen veya kullanım süresi dolan ürünler üreticiye iade edilerek genellikle uygun alanlarda yakma veya depolama ile bertaraf edilir [6]. İlaçların uygun olmayan depolama sahalarında bertaraf edilmesi durumunda sızıntı sularında bulunan ilaç atıkları 
yeraltı sularına ve yüzey sularına kadar ulaşabilir. Şekil 2'de veteriner ilaçlarının çevreye giriş yolları gösterilmektedir [7].

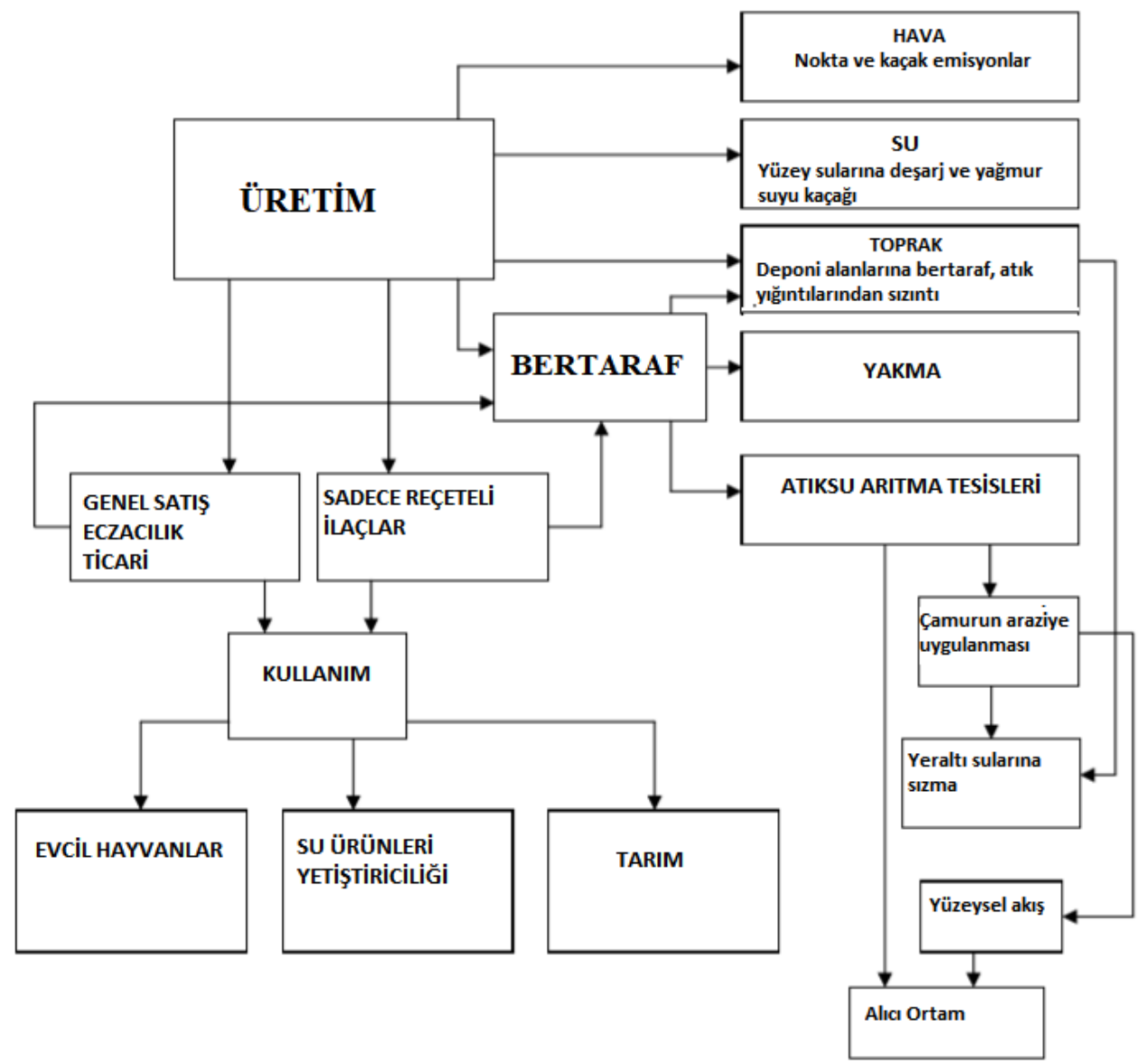

Şekil 2. Veteriner ilaçlarının çevreye giriş yolları

\subsection{Su Kültürü Yetiştiriciliğinde Kullanılan İlaçlar}

Balık yetiştiriciliğinde; kemoterapötik ilaçlar, anestezik maddeler, tıbbi dezenfektanlar ve anti-enfektif maddeler kullanılmaktadır. Balıklardaki bakteriyel enfeksiyonlar genellikle doğrudan kafeslere eklenen ilaçlı gıda peletleri kullanılarak tedavi edilmektedir [8]. İngiltere'de, su ürünleri yetiştiriciliğinde kullanılan altı antimikrobiyal madde; oksetetrasiklin, oksolinik asit, amoksisilin, florfenicol, sarafoksasin ve ko-trimazin için güncel satış yetkisi verilmiştir. Norveç'te daha geniş spektrumlu antimikrobiyaller ve ektoparazitisitler kullanılmaktadır. Son yirmi y1l boyunca, su ürünleri yetiştiriciliğinde kullanılan kemoterapötik ilaçların çevresel etkisini araştırmak için pek çok çalışma yapılmıştır [9].

\subsection{Antibiyotikler}

Antibiyotikler, mikroorganizmaları öldürebilen veya metabolik aktivitelerini biyokimyasal faaliyetlerle engelleyebilen ilaçlardır ve bakterilerin neden olduğu hastalıkların tedavisinde ve önlenmesinde kullanılırlar. Ayrıca veteriner hayvanlarının enfeksiyonlarını tedavi etmek veya önlemek için yem katkı maddesi olarak da uygulanırlar. 1998'de AB'de hayvancılıkta büyümeyi teşvik etmek için yemlere antibiyotiklerin eklenmesi yasaklanmış olsa da, hayvan üretiminde antibiyotik kullanımı dünya çapında yaygın bir şekilde kabul edilmektedir [10]. Tetrasiklinler en yaygın kullanılan antibakteriyel ilaçlardır, bunu güçlendirilmiş sülfonamidler, $\beta$-laktamlar, makrolitler, aminoglikozitler, fluorokinolonlar takip etmektedir. Veteriner antibiyotikleri, insanlarda kullanılan antibiyotiklerle benzer özellikler gösterse de bazı farklılıklar vardır, bunların çoğu hayvan bağırsağında az miktarda emilir, bu nedenle uygulanan dozun çoğu dışkı tarafından atılır [11]. İngiltere'de, veteriner ilaçları veya büyüme destekleyicileri 
olarak kullanılan antimikrobiyal ürünlerin satışında veriler mevcuttur. $\mathrm{Bu}$ veriler, ilaç endüstrisinin Veteriner İlaç Müdürlüğüne verdiği bilgilere dayanmaktadır [12].

\subsection{Oksolinik Asit}

Kültür balıklarının ilaçla tedavisi sırasında, çevredeki yabani balık popülasyonunda ve diğer deniz hayvanlarında oksolinik asit kalıntılarına rastlanmıştır. Yapılan çalışmalarda Norveç'in batı kıyısındaki su ürünleri yetiştiriciliği tesisinin yakınlarındaki yabani faunada oksolinik asit kalıntıları tespit edilmiştir. Baltık Denizi'nde bulunan beş balık çiftliğinde yapılan bir çalışmada, 24 balık türünün hiçbirinde oksolinik asite rastlanmamıştır [13]. Diğer bir çalışmada ise iki ayrı balık çiftliğinden toplanan 11 farklı türdeki balık, yengeç ve midyede oksolinik asit kalıntıları tespit edilmiştir. Finlandiya'nın güneybatı sahilinde yapılan bir çalışmada, balıkların yetiştirildiği beş balık çiftliğinin üçünün tabanından toplanan anoksik sedimentlerde oksolinik asit kalıntıları bildirilmiştir. Balık çiftliğinden beş gün boyunca alınan sedimentlerde $0,05-0,2 \mu \mathrm{g} / \mathrm{g}$ konsantrasyonlarında oksolinik asit rapor edilmiştir [14].

\subsection{Oksitetrasiklin}

Su ürünleri yetiştiriciliğinde kullanılan oksitetrasiklinin çevresel akibeti kapsamlı bir şekilde incelenmiştir [14,15]. Finlandiya'nın güneybatı sahilinde yapılan bir çalışmada iki ayrı balık çiftliğinde balıkların yetiştirildiği kafeslerin yakınında inci balığı ve çamça balığı örnekleri toplanmıştır. Oksitetrasiklin konsantrasyonlarının tedavinin son gününde çiftlik A'dan toplanan inci balığının kas dokusunda $0,06-1,3 \mu \mathrm{g} / \mathrm{g}$ arasında olduğu görülmüştür. İlaçlamadan bir gün sonra bir balıkta 0,06 $\mu \mathrm{g} / \mathrm{L}$ 'lik bir konsantrasyonda oksitetrasiklin tespit edilmiştir. Çiftlik B'de, ilaçlama yapıldıktan sonra 1. ve 2. günlerde toplanan çamça balığı örneklerinde çok düşük seviyelerde oksitetrasiklin bulunmuştur $(0,05-0,1 \mu \mathrm{g} / \mathrm{L})$. Benzer şekilde, Washington'da yapılan yeni bir çalışmada yabani faunada düşük konsantrasyonlarda oksitetrasikline rastlanmıştır. Yüksek miktarda antibakteriyel kullanan bir somon balıkçıllğı tesisinin etrafındaki alandan yengeçler ve istiridyeler toplanmıştır. İstiridye ve yengeçlerde sadece eser miktarda oksitetrasiklin kalıntıları (yaklaşı $0,1 \mu \mathrm{g} / \mathrm{g}$ ) bulunmuştur. Norveç'te, ilaçlama yapıldıktan 1, 4, 10 ve 12 hafta sonra dört farklı balık çiftliğinin tabanından alınan sedimentlerde oksitetrasiklin kalıntıları bulunmuştur [15]. Finlandiya'nın güneybatı sahilindeki Baltık Denizi'ndeki bir çalışmada, iki ayrı balık çiftliğinde ilaçlamanın son gününde toplanan sediment örneklerinin 0,05-3,8 $\mu \mathrm{g} / \mathrm{g}$ arasında değişen konsantrasyonlarda oksetetrasiklin içerdiği bildirilmiştir [14]. Çin'de sığır, domuz ve tavuk çiftliklerinin bulunduğu hayvancılık tesislerinin yakınındaki nehirlerden alınan sedimentlerde çeşitli antibiyotikler bulunmuştur. Domuz çiftliklerine yakın sedimentlerde sırasıyla $3106 \mathrm{ng} / \mathrm{L}$ ve 1957 ng/L'ye kadar yükselen oksitetrasiklin ve klorotetrasiklin konsantrasyonları tespit edilmiştir [16].

\section{5 İvermektin}

Oral uygulamayı takiben, ivermektin esas olarak değişmeyen bir formda dişarı atılır. Bu bağlamda, çeşitli modelleme yaklaşımlarında ivermektinin balık çiftliklerinin tabanındaki sedimentlerde ne kadar birikeceği tahmin edilmeye çalışılmıştır. Bir izleme çalışmasında, İrlanda'nın yaklaşık 1 km açık deniz kıyısına sahip olan batı kıyısında somon kafeslerin yakınındaki sedimentlerde ivermektin tespit edilmiştir. Sediment örnekleri ilacın haftada iki kez uygulandığı dört aylık bir periyodun son gününde toplanmıştır. Kafeslerden $31 \mathrm{~m}$ uzakta toplanan sedimentlerde, 1,4 ile 6,8 $\mathrm{ng} / \mathrm{g}$ arasındaki konsantrasyonlarda ivermektin tespit edilmiştir. Almanya'da yapılan çalışmalarda ise çiftlik hayvanlarının tedavisinde kullanılan ilaç konsantrasyonlarına dair veriler elde edilmiştir. İzleme verilerinin özetleri ve analitik yöntemlerin kullanılabilirliği Tablo 1'de verilmiştir [17]. 
Tablo 1. Toprak, sediment, yüzeysuları ve yeraltı sularında tespit edilen veteriner ilaçların çevredeki konsantrasyonlar1

\begin{tabular}{|l|l|l|l|l|}
\hline & \multicolumn{3}{|c|}{ Belirlenen konsantrasyon aralığ1 } \\
\hline Bileşik & $\begin{array}{l}\text { Yüzey suları } \\
\text { ng/L }\end{array}$ & $\begin{array}{l}\text { Yeraltı suları } \\
\text { ng/L }\end{array}$ & $\begin{array}{l}\text { Toprak } \\
\mu \mathrm{g} / \mathrm{kg}\end{array}$ & $\begin{array}{l}\text { Sediment } \\
\mu \mathrm{g} / \mathrm{kg}\end{array}$ \\
\hline Kloramfenikol & $0,06 \mu \mathrm{g} / \mathrm{L}$ & - & - & - \\
\hline Klorotetrasiklin & $0,5 \mu \mathrm{g} / \mathrm{L}$ & $0,17-0,22 \mu \mathrm{g} / \mathrm{L}$ & $0,7 \pm 0,2-41,8$ & - \\
\hline Sipermetrin & $1-85100$ & - & - & - \\
\hline Diazinon & $3-0,58 \mathrm{x} 10^{6}$ & 216 & - & - \\
\hline Desmetilamino metaboliti & - & - & - & $>0,5$ \\
\hline Fenklorfos & $<10-777$ & - & - & - \\
\hline Flumetrin & $1-2190$ & - & - & - \\
\hline İvermektin & - & - & $0,1-2$ & $6,8 \mathrm{ng} / \mathrm{L}$ \\
\hline Monensin & - & - & $0,8-1,08 \mathrm{mg} / \mathrm{kg}$ & - \\
\hline Oksolinik asit & - & - & - & $<0,05-0,2 \mu \mathrm{g} / \mathrm{g}$ \\
\hline Oksitetrasiklin & - & $0,15-0,19 \mu \mathrm{g} / \mathrm{L}$ & $0,9 \pm 0,1-8,6 \pm 4,5$ & $0,1-285 \mu \mathrm{g} / \mathrm{g}$ \\
\hline Sulfamethazine & - & $0,08-0,16 \mu \mathrm{g} / \mathrm{L}$ & - & - \\
\hline Tetrasiklin & - & $0,11-0,27 \mu \mathrm{g} / \mathrm{L}$ & $<1-39,6 \pm 33,6$ & - \\
\hline Tilosin & - & $0,13-0,42 \pm 0,47 \mu \mathrm{g} / \mathrm{L}$ & 0,2 & \\
\hline
\end{tabular}

\section{Veteriner İlaçlarının Metabolizması}

Veteriner ilaçları vücuda alındıktan sonra metabolize edilmekte ve ortaya çıkan metabolitler idrar ve dışkı ile birlikte atılmaktadır. Çevreye bırakıldıktan sonra veteriner ilaçları çevresel ortamlar içinde (toprak, hava, yüzey suları, sediment ve biyota) taşınmakta ve dağılmaktadır. Çevresel ortamlardaki konsantrasyonlar, aşağıda belirtilen bir dizi faktör ve süreç tarafindan belirlenir:

- $\quad$ Bileşiğin dozaj1

- $\quad$ Maddenin fiziko-kimyasal özellikleri

- $\quad$ Gübre ve gübre çamurunun ayrışması

- $\quad$ Toprak ve sedimentin yapisina katılma

- $\quad$ Abiyotik ve biyotik ayrışma

- $\quad$ Çevresel özellikler (toprak tipi, iklim koşulları)

Bileșik vücut tarafindan adsorbe edildiğinde faz I ve faz II şeklinde metabolize edilip vücuttan atılmaktadır. Bu reaksiyonlar sonucu, idrar veya dışkıyla atılan polar metabolitler üretilebilir. Eğer bileşik metabolize edilmezse, değişmeden atılabilir. Sonuç olarak, hayvan dışkıları ana bileşik ve metabolitlerinin bir karışımını içerebilir. Ana bileşik ve temel metabolitlerinin çevresel etkileri herhangi bir risk değerlendirmesinde dikkate alınmalıdır [17].

\section{Veteriner İlaçlarının Bertarafi}

İngiltere'de, "kontrollü" atıkların ve "özel" atık olan veteriner ilaçlarının bertaraf edilmesi için yasal düzenlemeler bulunmaktadır. Reçeteli ilaçlar sadece özel atık olarak sınıflandırılmaktadır. İlaç üreticileri tarafindan sağlanan ürün etiketi ve güvenlik veri sayfaları, veteriner ilaçlarının ve ambalajlarının güvenli bir şekilde bertaraf edilmesine ilişkin bilgiler vermektedir. Kullanılmayan veteriner ilaçları veteriner cerrahi ve yerel eczanelere iade edilebilir. Veteriner ilaçları yerel kullanıcılar tarafindan ya direkt tuvaletlerden kanalizasyon sistemine atılmakta ya da yakma ve evsel atıklarla birlikte bertaraf edilmektedir [18]. Üretim tesisleri, emisyonları kontrol etmek ve üretilen atık miktarını en aza indirmek için pek çok arıtma metodolojisi ve teknolojisini kullanmaktadır. Bunlar, kondansatörler, gaz temizleyiciler, adsorban filtreler ve hava emisyonlarında geri kazanım ve giderim için yakma teknolojilerini içermektedir. Atıksuların arıtılması için nötralizasyon, dengeleme, aktif çamur, birincil arıtma, filtrasyon, aktif karbon, kimyasal oksidasyon ve ileri biyolojik arıtma kullanılabilir. 


\section{Veteriner İlaçlarının Çevresel Ortamdaki Akibeti}

Veteriner ilaçlarının çevreye salınması, ya doğrudan balık çiftliklerinde kullanılan ilaçların kullanımı ya da hayvan gübresinin toprağa uygulanması yoluyla dolaylı olarak gerçekleşmektedir. Çevreye salınan veteriner ilaçlarının miktarları; hayvancılık uygulamaları, tedavi tipi ve dozu, hayvan metabolizması, gübre ve gübre çamurundaki bozunma oranları gibi çeşitli faktörlere bağlıdır. Veteriner ilaçlarının karasal ortamlara girişinde temel yol, hayvancılıkta veteriner ilaçlarının kullanılması ve gübrenin toprağa uygulanması yoluyla olmaktadır. Ayrıca gübrenin toprağa uygulanması ile veteriner ilaçları su yüzeyine ve/veya yeraltı sularına sızma yoluyla da girmektedir [19].

\subsection{Toprak}

Bir veteriner ilacı toprağa ulaştığında, toprak parçacıkları tarafından adsorblanmakta, yeraltı suyuna sızmakta ve/veya ayrışmaktadır. Antibiyotikler, koyun yıkama havuzundaki kimyasallar ve topraktaki ivermektinlerin sorpsiyon davranışları üzerine hali hazırda veriler mevcuttur. Topraktaki veteriner ilaçlarının kalıcılığı ve sorpsiyon davranışları ile ilgili çok sayıda çalışma yapılmıştır. Bazı veteriner ilaçlarının topraklardaki sorpsiyon davranışları ile ilgili veriler mevcuttur. Dağılım katsayıları (Kd), 0,61 $\mathrm{L} / \mathrm{kg}$ ile $6000 \mathrm{~L} / \mathrm{kg}$ arasında değişmektedir. Çiftlik hayvanlarını tedavi etmek için kullanılan kortetrasiklin, ivermektin ve monensinin topraktaki konsantrasyonları, sirasıyla $42 \mu \mathrm{g} / \mathrm{kg}, 2 \mu \mathrm{g} / \mathrm{kg}$ ve 1 $\mathrm{mg} / \mathrm{kg}$ kadar yüksektir. Veteriner ilaçlarının topraklarda parçalanması için temel yol toprakta aerobik biyobozunmadır. Veteriner ilaçları günlerce hatta yıllarca toprakta kalabilmekte ve yarı ömürleri sıcaklık, $\mathrm{pH}$, gübre varlığı ve ilaç gruplarını parçalamak için geliştirilen spesifik bakterilerin mevcudiyeti gibi çeşitli faktörlerden etkilenmektedir [19,20].

Gübre içindeki bozunma oranları genellikle topraktaki bozunmadan daha hızlıdır. Örneğin, metanojenik koşullar altında, tylosin A'nın bozunması iki günden daha az sürede gerçekleşmiştir ve aerobik koşullar altında inkübasyon ortamında gübre konsantrasyonuna bağlı olarak artmıştır [21]. Sıcaklığın bir bileşiğin bozunma hızını hangi ölçüde etkilediğini göstermek için çalışmalar yapılmıştır. Örneğin, soğuk hava koşullarında bir toprak/dışkı karışımında ivermektin için 91 ila 217 günlük bir yarı ömür tespit edilmiştir. Buna karşılık, bileşiğin yaz aylarında bir toprak/dışkı karışımında çok daha hızlı bozunduğu ve 7 ila 14 günlük bir yarı ömre sahip olduğu gösterilmiştir [22]. Veteriner ilaçlarının topraktaki hareketliliği, çevredeki veteriner ilaçlarının konsantrasyonunun belirlenmesinde etkilidir. Yapılan bir çalışmada farklı toprak tiplerindeki dört antibiyotiğin sorpsiyonu ve hareketliliği belirlenmiştir. Kesikli deneylerle belirlenen dağılım katsayılarının (Kd değerleri), metronidazol için 0,50,7, olaquindox için 0,7-1,7 ve tilosin için ise 8-128 arasında olduğu rapor edilmiştir [23].

Yoğun hayvancılık yapılan bölgelerden toplanan toprak örneklerinde ilaç analizleri yapılmıştır. Hayvan gübresi ile iyileştirilmiş toprakta çeşitli veteriner ilaçları tespit edilmiştir. İlk çalışmada toprak numuneleri örnekleme işleminden iki gün sonra gübrelenmiş bölgenin çeşitli derinliklerinden toplanmıştır [24]. Toprak örneklerinin üst $10 \mathrm{~cm}$ 'sinde $9-12 \mu \mathrm{g} / \mathrm{kg}$ klorotetrasilin, oksitetrasilin ve tetrasilin saptanırken, sadece düşük konsantrasyonlarda tilosin bulunmuştur. Üç farklı tetrasilin bileşiğinin konsantrasyonu $60 \mathrm{~cm}$ 'nin altındaki derinliklerde $1 \mu \mathrm{g} / \mathrm{kg}$ ' a kadar düşmüştür. Kuzey Almanya'da yapılan bir diğer çalışmada, toprak örnekleri hayvan gübresi uygulandıktan 4-5 ay sonra 12 farklı tarım alanından alınmış ve analiz edilmiştir. Toprak örneklerinin neredeyse hepsinin üst 30 cm'sinde $1-32,2 \mu \mathrm{g} / \mathrm{kg}$ ve 1,2-26,4 $\mu \mathrm{g} / \mathrm{kg}$ konsantrasyonlarında tetrasilin ve klorotetrasilin saptanmıştır. Aynı araştırmacılar tarafindan yapılan başka bir çalışmada, hayvan gübresi uygulanan toprağın üst 30 cm'sinde 20-40 $\mu \mathrm{g} / \mathrm{kg}$ arasında tetrasilin konsatrasyonları tespit edilmiştir [25].

\subsection{Yüzeysel Sular}

Atıksu arıtma tesislerinden arıtılmadan ya da kısmen artılmış olarak alıcı ortama deşarj edilen farmasötiklere sucul ortamlarda, kanalizasyon atıksularında ve yüzeysel sularda rastlanılması büyük ilgi kaynağ 1 olmuştur [26,27]. Organofosforlu bileşiklerden klorfenvinfos ve diklorvoların hepsi biyolojik olarak aktif sularda nispeten hızlı bir şekilde bozunmakta; fakat sentetik piretroid ve flumetrin ise kalıcı olmaktadır. Sedimentlerde furazolidonun yanı sıra fenitollerin (kloramfenikol ve florfenikol) hızla bozunduğu, 2,4 diaminopirimidin, kinolon, tetrasiklin ve sülfonamid sınıflarının hepsinin kalıcı olduğu görülmüştür [28-30]. Veteriner ilaçlarının yüzey sularında ve tatlı su ve deniz sedimentindeki kalıcılığını 
araştırmak için çalışmalar yapılmıştır. Alman araştırmacılar tarafindan yapılan çalışmalarda arıtma tesisi çıkış suları ve yüzey sularında 0,06-0,56 $\mu \mathrm{g} / \mathrm{L}$ konsantrasyonlarında 18 farklı antibiyotik tespit edilmiştir. ABD Çevre Koruma Ajansı (USEPA) ve ABD Jeolojik Araştırma grubu (USGS), domuz ve kümes hayvanı üretiminin yapıldığı bölgenin yakınındaki yüzey ve yeraltı sularından, domuz lagünlerinden alınan sıvı atıkları analiz etmişlerdir. Klorotetrasilin lagün örneklerinde çok yüksek konsantrasyonlarda tepit edilirken, yüzeysel sularda $0,5 \mu \mathrm{g} / \mathrm{L}$ (tespit limiti) konsantrasyonunda bulunmuştur [31]. Koyun ilaçlama havuzlarında kullanılan ilaçların konsantrasyonları yüzey sularında 19,2-106 ng/L, yeraltı sularında ise $489 \mathrm{ng} / \mathrm{L}$ kadar yüksek olarak rapor edilmiştir. Su kültürü yetiştiriciliğinde kullanılan ilaçların konsantrasyonları yüzey sularında $1 \mu \mathrm{g} / \mathrm{L}$, sedimentlerde ise 285 $\mu \mathrm{g} / \mathrm{g}$ ' a kadar çıkmaktadır [28].

\subsection{Yeraltı Suları}

Yeraltı sularında tespit edilen az sayıda veteriner ilacı raporları vardır [29,30]. Veteriner ilaçları çöp depolama alanlarından yeraltı sularına sızmaktadır. Danimarka'da bir ilaç üreticisinin atıklarının büyük bir kısmını 45 yıldır bertaraf ettiği bir depolama sahasının sızıntı sularında çok sayıda sülfonamidin yüksek konsantrasyonlarına rastlanmıştır [31]. Almanya'da yürütülen kapsamlı bir izleme çalışmasında, antibiyotiklerin kontaminasyon derecesini belirlemek için tarım alanlarından çok sayıda yeraltı suyu örneği toplanmıştır ve analiz edilmiştir [32]. Oksitetrasiklin, tetrasiklin, klortetrasiklin ve tilosin yeraltı sularında tespit edilmiştir [33,34]. Sığır ve domuz besleme tesisleri ile bağlantılı olan yeraltı sularında eritromisin (72-2380 ng/L) ve monensin $(180-2350 \mathrm{ng} / \mathrm{L})$ gibi bazı veteriner ilaçlarına rastlanmıştır. Ayrıca yeraltısuyu örneklerinde sulfamerazin, sulfametazin, sulfametazol ve sulfatizol gibi sulfanomidler tespit edilmiştir [35].

\subsection{Gübre ve Gübre Çamuru}

Hayvan çiftliklerinde fazla miktarda çiftlik gübresi (kirli yatak malzemesi ile birlikte hayvan idrarı ve dışkı) ve/veya gübre çamuru (idrar, dışkı ve yıkama suyu) üretilmektedir. Gübreler sonraki uygulamalar için gübre çukurlarında saklanmakta veya organik madde takviyesi ve toprak iyleştiricisi olarak toprağa uygulanmaktadır. Sulfonamidler, aminoglikozitler, beta-laktamlar ve makrolidlerin yarı ömürleri 30 gün veya daha düşüktür ve bu nedenle gübre/gübre çamurunda depolama sirasında önemli ölçüde ayrışmaktadırlar. Bunun aksine, makrolid endektin, ivermektin, tetrasiklinler ve kinolonların yarı ömürleri daha fazladır ve bu nedenle daha kalıcı olmaları muhtemeldir. Bazı veteriner ilaçları, gübrenin araziye uygulanmasından sonra toprak veya yüzey partiküllerine güçlü bir şekilde adsorblanmaktadır [25].

\subsection{Aritma Tesisleri}

Sucul ortamlarda bulunan ve insani amaçlı tüketilen farmasötik bileşiklerin biyolojik arıtım proseslerinde giderimi ile ilgili çalı̧̧malar bulunmaktadır [36-38]. Evsel atıksu arıtma tesislerinde rastlanan insani amaçlı tüketilen farmasötiklerden farklı olarak çevresel ortamlarda da farmasötik bileşiklere rastlamak, noktasal kaynaklardan ziyade daha çok dağınık kaynaklar ile ilgilidir ve atıksu arıtma tesisleri ile ilgili pek fazla çalışma yapılmamıştır. Bununla birlikte Kanada'daki atıksu arıtma tesisi çıkış sularındaki ilaçların varlığı ve konsantrasyonu araştırılmıştır ve elde edilen veriler diğer ülkelerde gözlemlenen maksimum konsantrasyonlarla karşılaştırılmıştır. Veteriner uygulamalarında kullanılan ve bir antibiyotik olan sülfametazin 3,278 g/L konsantrasyonunda tespit edilmiştir [39]. Veteriner ilaçları evsel atıksu arıtma tesislerine bir kaynak teşkil etmezken, hayvan besleme tesislerindeki atıksular çevresel ortamlar için potansiyel bir kaynak teşkil etmektedir [35]. Sığır ve domuz tesislerinden elde edilen atıksu örneklerinde linkomisin, raktopamin, sulfametazin, sulfatizol, eritromisin, tiamulin ve sulfadimetoksin tespit edilmiştir. Hayvancılığa ait atıksu arıtma tesislerinde veteriner ilaçlarının bulunuşu ile ilgili yapılan çalışmada, yüksek konsantrasyonlarda antelmintik fenbendazol ve metabolitleri $(3,85-241 \mu \mathrm{g} / \mathrm{L})$, fenbenzadol sülfon $(0,283-93,9 \mu \mathrm{g} / \mathrm{L})$, amino fenbendazol $(0,554-94,1 \mu \mathrm{g} / \mathrm{L})$ ve p-hidroksi fenenzadol $(0,693-92,7 \mu \mathrm{g} / \mathrm{L})$ tespit edilmiştir [40]. 


\subsection{Tatlısu Kaynakları}

Tatlı su kaynaklarındaki farmasötiklerin tespit edilmesi için çok sayıda çalışma yapılmıştır. Kore'de bir domuz gübresi kompostlama tesisine yakın Naerincheon nehri boyunca yer alan yüzey sularında antibiyotiklerin mevsimsel değişimi çalışılmıştır. Evsel atıksu arıtma tesisinin yakınında bulunan Kore nehir sularında antihelmintik fenebendazol ve metobilitleri çok düşük konsantrasyonlarda (0,006-1,31 $\mu \mathrm{g} / \mathrm{L}$ ) tespit edilmiştir [40]. Avustralya'da süt çiftliklerinin yakınındaki dere ve nehirlerinin bulunduğu sulama alanından alınan örneklerde penisilin, sulfanomidler ve tetrasiklinlerin akibetleri araştırılmıştır. Süt çiftliklerine yakın yerlerdeki örnekleme noktalarında sulfasazalin (202-321 ng/L) ve oksitetrasiklin (109-423 ng/L) tespit edilmiştir. Başta domuz çiftlikleri olmak üzere çok sayıda tarımsal kuruluşun bulunduğu ülkenin bir bölümünden geçen İspanya'daki Llobregat Nehri'nin sularında antelmintiklerin varlığı araştırılmıştır. Yapılan çalışmada 0,32 ve 39,43 ng/L aralığında değişen konsantrasyonlarda antihelmintikler tespit edilmiştir [41]. Bir antihelmintik olan levamisolun ise yüksek konsantrasyonda $(39,43 \mathrm{ng} / \mathrm{L})$ bulunduğunu bildirmişlerdir [42]. Sucul ortamdaki veteriner ilaçlarının konsantrasyon aralıkları ve bu ilaçların tespiti için kullanılan analitik yöntemler Tablo 2'de gösterilmiştir [43].

Tablo 2. Sucul ortamdaki veteriner ilaçlarının konsantrasyonları ve tespiti için kullanılan analitik yöntemler

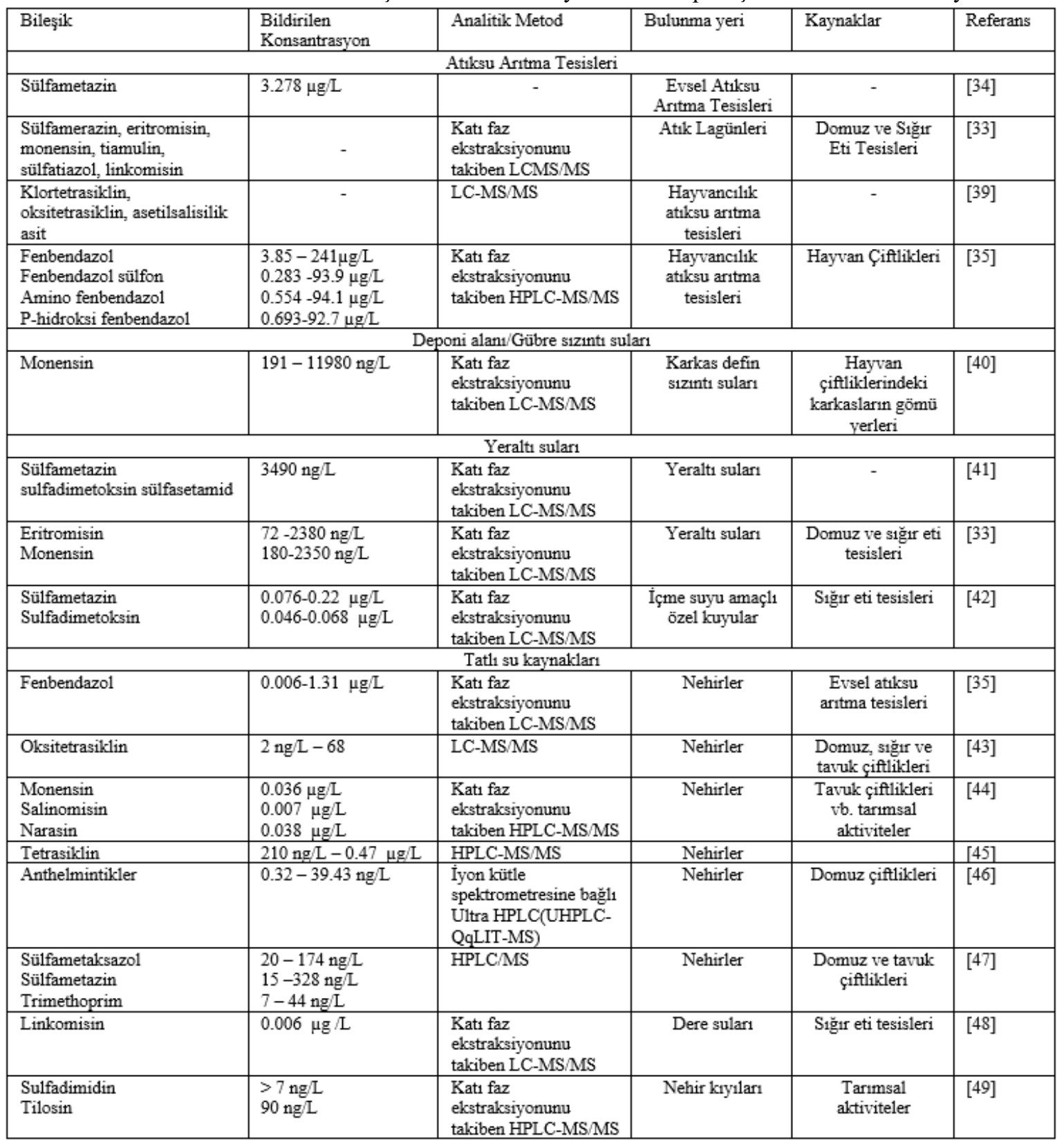




\section{Sucul Ekosistemler ve İnsan Sağlığı Üzerindeki Riskleri ve Toksisitesi}

Veteriner ilaçlarının toksisitesi hakkında yapılan laboratuar çalışmaları sayesinde bireysel organizmalar grubuna ait veriler mevcuttur. Birtakım veteriner ilaçlarının endokrin sistemi bozucu aktivite sergilediği gösterilmiştir. Fakat sınırlı bilgi nedeniyle, veteriner ilaçlarını çevredeki endokrin bozulmasının bir nedeni olarak değerlendirmek zordur. Öncelikli tanımlanan bu bileşiklerin çevrede ekolojik olarak önemli seviyelerde bulunup bulunmadığını belirlemek için çevresel izlemenin yapılması gerekmektedir [38].

Antibiyotikler, antiparazitik ve antifungal ilaçlar, hormonlar, anti-inflamatuar ilaçlar, anestezikler, sedatifler gibi geniş ölçekteki veteriner ilaçları çevreye salınırlar ve bitkilerde dâhil olmak üzere hedef dışı organizmaları etkileyebilirler. İvermektinlerin ve koyun yıkama kimyasallarının sucul organizmalar üzerindeki akut ve kronik etkileri belirlenmiştir ve bu maddelerin düşük konsantrasyonlarda bile çeşitli organizmalar için toksik olduğu bilinmektedir (ng/L ve $\mu \mathrm{g} / \mathrm{L}$ ). Dünya Sağlık Örgütü'ne (WHO) göre, çevrede bulunan veteriner ilaçlarının su ve toprak matrislerinde dirençli antibiyotiklerin gelişmesinden sorumlu olduğu belirtilmektedir. Son yıllarda ABD ve Avrupa'da veteriner ilaçlarının çevresel risk değerlendirmelerinin oluşturulması ve gereklilikleri ile son gelişmeler giderek hız kazanmaktadır [55]. Farmasötiklerin sucul organizmalardaki uzun vadeli etkilerini değerlendirmek için çok fazla araştırma yapılmasına rağmen, bunların sayısının hala çok düşük olduğunu belirtilmektedir [56]. Yapılan araştırmalarda metabolitlerin ve bozunma ürünlerinin potansiyel etkileri araştırılmıştır ve çok sayıda veri mevcut olmasına ve bilimin ilerlemeye devam etmesine rağmen yapılması gereken çok şey vardır. Veterinerlik bileşiklerinin toksik etkileri ve bunlarla ilişkili riskler hakkında bilgi edinmek için; kullanılan miktarlar, çevresel izleme, türlerin duyarlılık dağılımı, biyolojik birikim potansiyeli, endokrin bozunma potansiyeli ve daha yüksek trofik seviyeli türler üzerinde dolaylı etkileri gibi farklı alanlarda yapılmış çalışmalara ihtiyaç vardır.

Tarım ve su ürünleri yetiştiriciliği nedeniyle hayvanlarda ilaç kullanımının giderek artması çevresel risklerin artmasına neden olmuştur. $\mathrm{Bu}$ bileşikler dirençli bakteri populasyonlarının gelişmesine, mikrofauna ve mikroflora üzerinde toksisiteye ve sonuçta olumsuz ekolojik etkilere sebep olmaktadır. Diğer farmasötik bileşik özellikle de antibakteriyel maddelerin sucul ve karasal toksisitesine ilişkin yapılan çalışmalar vardır. Bazı alg ve sucul bakteri türleri için toksisite daha fazladır. Genel olarak antibakteriyel maddeler için toksisite değerleri bildirilen çevresel konsantrasyonlardan önemli ölçüde yüksektir. Bununla birlikte, uygun toksisite verilerinin eksikliği nedeniyle, bu gözlemlerin çevresel önemini uzun vadeli etkiler açısından değerlendirmek zordur [57].

\section{Sonuç}

Veteriner ilaçlarından kaynaklanan çevresel potansiyel risklerin daha iyi anlaşılması için tüm genel veteriner ilaç gruplarının kullanımı, maruz kalma yolları, çevresel akibeti, davranışları ve etkileri hakkındaki mevcut veriler harmanlanmış ve incelenmiştir. Literatürde çeşitli veteriner ilaçları için analitik yöntemler bulunmaktadır. Bunlar genel olarak gıdalardaki veteriner ilaç konsantrasyonlarının belirlenmesi için geliştirilmiştir. Bununla birlikte yüzey suları, sedimentler, gübre/gübre çamuru, topraklar ve yeraltı sularında seçilen bileşikler için sınırlı sayıda metotlar mevcuttur. Yüzey sularında koyun yıkama kimyasalları için tespit edilen konsantrasyonlar $106 \mathrm{ng} / \mathrm{L}$ ve yeraltı sularında $489 \mathrm{ng} / \mathrm{L}$ 'ye kadar yükselmiştir ve genellikle bu değerler Çevresel Kalite standartlarında verilen değerleri aşmaktadır. Su ürünleri yetiştiriciliğinde kullanılan veterinerlik ürünlerinin rapor edilen konsantrasyonları suda $1 \mu \mathrm{g} / \mathrm{L}$ (emamektin benzoat) ve sedimentte $285 \mu \mathrm{g} / \mathrm{g}$ kadar yüksektir (oksitetrasiklin). Çiftlik hayvanlarını tedavi etmek için kullanılan antibakteriyel maddelerin ve antihelmentiklerin konsantrasyonları hakkında sinırlı miktarda veri mevcuttur. Toprakta klortetrasilin, ivermektin ve monensinin bildirilen maksimum konsantrasyonları sirasiyla $42 \mu \mathrm{g} / \mathrm{kg}, 2 \mu \mathrm{g} / \mathrm{kg}$ ve 1 $\mathrm{mg} / \mathrm{kg}$ 'dır. Bu veriler veteriner ilaçlarının çevre üzerindeki etkilerinin risk değerlendirmesi ve bu etkileri en aza indirmeyi hedefleyen politika belirleme ve düzenleme önlemleri için gereklidir.

Tetrasiklinler, tiyamfenikoller, florokinolonlar, makrolidler ve sülfonamitleri içeren çok sayıda madde için mevcut veriler sınırlıdır. Bu nedenle birçok durumda kronik veri bulunmadığından ve farklı türlerin bağıl duyarlılı̆̆ bilinmediğinden bu maddelerin etkilerini tam olarak değerlendirmek zordur.

Veteriner ilaçlarının çevresel etkilerin tespiti, nicelleştirilmesi ve değerlendirilmesi gibi mevcut zorlukların üstesinden gelmek gerekmektedir. Günümüzde bu konular ile ilgili daha fazla araştırmaların 
yapılmaya başlanmasıyla bu bileşiklerin davranışları, sucul ve karasal organizmalarda meydana getirdiği riskler hakkındaki bilgilere daha hızlı bir şekilde ulaşmak mümkün olacaktır. Veteriner ilaçlarının çevresel etkilerini daha iyi anlamak ve uygun risk azaltma önlemlerinin alınmasını sağlamak için öncelikli olarak tanımlanan veteriner ilaçları için daha fazla çalışma yapılması gerekmektedir.

\section{Yazarların Katkısı}

Makalenin yazımında yöntemin tasarlanması ve planlanması, literatürün taranması ve derlenmesi ve en sonunda makalenin basım aşamasına gelinceye kadar tüm düzeltme ve son kontroller tek yazar Ayşe ÖZGÜVEN tarafindan yapılmıştır.

\section{Çıkar Çatışması Beyanı}

Yazarlar arasında herhangi bir çıkar çatışması bulunmamaktadır.

\section{Araştırma ve Yayın Etiği Beyanı}

Yapılan çalışmada, araştırma ve yayın etiğine uyulmuştur.

\section{Kaynaklar}

[1] Reemtsma T., Jekel M. (Eds.). 2006. Organic Pollutants in the Water Cycle: Properties, Occurrence, Analysis and Environmental Relevance of Polar Compounds. Water Chemical Society. 350pp.

[2] Environment Agency. 2001. Pesticides 1999/2000: A summary of monitoring of the aquatic environment in England and Wales, National Centre for Ecotoxicology and Hazardous Substances. Environment Agency, Wallingford.

[3] Environment Agency. 2000. Welsh sheep dip monitoring programme 1999. Environment Agency Wales, Cardiff. Environment Agency Midland Region, April 2001, Solihull.

[4] Davies I.M., Gillibrand P.A., McHenry J.G., Rae G.H. 1998. Environmental risk of ivermectin to sediment-dwelling organisms. Aquaculture, 163: 29-46.

[5] Arnold K.E., Boxall A.B., Brown A.R., Cuthbert R.J., Gaw S., Hutchinson T.H., Jobling S., Madden J.C., Metcalfe C.D., Naidoo V., Shore R. F., Smits J.E., Taggart M.A., Thompson H.M. 2013. Assessing the exposure risk and impacts of pharmaceuticals in the environment on individuals and ecosystems. Biol. Lett., 9 (4): 20130492.

[6] Jorgensen S.E., Halling-Sorensen B. 2000. Drugs in the environment. Chemosphere, 40: 691-699.

[7] Boxall A.B.A., Fogg L., Blackwell P.A., Key P., Pemberton E.I. 2002. Review of veterinary Medicines in the Environment R\&D Technical Report P6-012/8/TR. Environment Agency, Bristol, pp. 1-233, Bristol.

[8] Samuelsen O.B., Lunestad B.T., Husevag B., Holleland T., Ervik A.1992. Residues of oxolinic acid in wild fauna following medication in fish farms. Diseases of Aquatic Organisms, 12: 111119.

[9] Holm J.V., Rügge K., Bjerg P.L., Christensen T.H. 1995. Occurrence and distribution of pharmaceutical organic compounds in the groundwater downgradient of a landfill (Grinsted, Denmark). Environmental Science and Technology, 29: 1415-1420.

[10] Du L.F., Liu W.K., 2012. Occurence, fate and ecotoxicity of antibiotics in agro-ecosystems. A review. Agron. Sustain., Dev. 32 (2): 309-327.

[11] Bartikova H., Podlipna R., Skalovaa L. 2016. Veterinary drugs in the environment and their toxicity to plants. Chemosphere, 144: 2290-2301.

[12] VMD. 2001. Sales of antimicrobial products used as veterinary medicines and growth promoters in the UK in 1999. Report obtained from VMD website.

[13] Ervik A., Thorsen B., Eriksen V., Lunestad B.T., Samuelsen O.B. 1994. Impact of administering antibacterial agents on wild fish and blue mussels Mytilus edulis in the vicinity of fish farms. Diseases of Aquatic Organisms, 18: 45-5. 
[14] Björklund H.V., Bondestam J., Bylund G. 1990. Residues of oxytetracycline in wild fish and sediments from fish farms. Aquaculture, 86: 359-367.

[15] Capone D.G., Weston D.P., Miller V., Shoemaker C. 1996. Antibacterial residues in marine sediments and invertebrates following chemotherapy in aquaculture. Aquaculture, 145: 55-75.

[16] Wang N., Guo X., Xu J., Kong X., Gao S., Zhengjun S. 2014. Pollution characteristics and environmental risk assessment of typical veterinary antibiotics in livestock farms in Southeastern China. J. Environ. Sci. Health Part B., 49: 468-479.

[17] Canavan A., Coyne R., Kennedy D.G., Smith P. 2000. Concentration of 22,23dihydroavermectim B1a detected in the sediments at an Atlantic salmon farm using orally administered ivermectin to control sea-lice infestation. Aquaculture, 182: 229-240.

[18] Daughton C.G., Ternes T.A. 1999. Pharmaceuticals and personal care products in the environment; Agents of subtle change? Special report. Environmental Health Perspectives Supplements, 107: 907-938.

[19] Ingerslev F., Halling-Sorensen B. 2001. Biodegradability of metronidazole, olaquindox and tylosin and formation of tylosin degradation products in aerobic soil/manure slurries. Chemosphere, 48: 311-320.

[20] Gilbertson T.J., Hornish R.E., Jaglan P.S., Koshy T., Nappier J.L., Stahl G.L., Cazers A.R., Nappier J.M., Kubicek M.F., Hoffman G.A., Hamlow, P. 1990. Environmental fate of ceftiofur sodium, a cephalosporin antibiotic. Role of animal excreta in its decomposition. Journal of Agricultural and Food Chemistry, 38: 890-894.

[21] Loke M.L., Ingerslev F., Halling-Sorensen, B., Tjornelund J. 2000. Stability of tylosin A in manure containing test systems determined by high performance liquid chromatography. Chemosphere, 40: 759-765.

[22] Halley B.A., VandenHeuvel W.J.A., Wislocki P.G. 1993. Environmental effects of the usage of avermectins in livestock. Veterinary Parasitology, 48: 109-125.

[23] Rabolle M., Spliid N.H. 2000. Sorption and mobility of metronidazole, olaquindox, oxytetracycline and tylosin in soil. Chemosphere, 40: 715-722.

[24] Hamscher G., Sczesny S., Abu-Quare A., Höper H., Nau H. 2000. Substances with pharmacological effects including hormonally active substances in the environment: Identification of tetracyclines in soil fertilised with animal slurry. Dtsch. tierärztl. Wschr. 107:293-348.

[25] Hamscher G., Sczesny S., Höper H., Nau H. 2000a. Tetracycline and chlortetracycline residues in soil fertilized with liquidmanure. Proceedings of Livestock Farming and the Environment, 2829 September, Hannover.

[26] Balci B., Erkuş A., Erkuş F.Ş. 2010. Farmasötik bileşiklerin sucul ortamda bulunuşu ve etkileri, Biyoloji Bilimleri Araştırma Dergisi, 3: 13-19.

[27] Heberer T, 2002. Occurrence, Fate, and Removal of Pharmaceutical Residues in the Aquatic Environment: a review of recent research data. Toxicol. Letters, 131: 5-17.

[28] Ayscough N.J., Fawell J., Franklin G., Young W. 2000. Review of human pharmaceuticals in the environment. Environment Agency R \& D Technical Report, 390ss.

[29] Hartig C., Storm T., Jekel M. 1999. Detection and identification of sulphonamide drugs in municipal waste water by liquid chromatography coupled with electrospray ionisation tandem mass spectrometry. Journal of Chromatography A, 854: 163-173.

[30] Ternes T.A. 1998. Occurrence of drugs in German sewage treatment plants and rivers. Water Research, 32: 3245-3260.

[31] Meyer M.T., Bumgarner J.E., Varns J.L., Daughtridge J.V., Thurman E.M., Hostetler K.A. 2000. Use of radioimmunoassay as a screen for antibiotics in confined animal feeding operations and confirmation by liquid chromatography/mass spectrometry. The Science of the Total Environment, 248: 181-187.

[32] Hirsch R., Ternes T., Heberer K., Kratz, K.L.1999. Occurrence of antibiotics in the aquatic environment. The Science of the Total Environment, 225: 109-118.

[33] McKellar Q.A. 1997. Ecotoxicology and residues of anthelmintic compounds. Veterinary Parasitology, 72: 413-435.

[34] Strong L. 1993. Overview: the impact of avermectins on pastureland ecology. Veterinary Parasitology, 48: 3-17. 
[35] Bartelt-Hunt S., Snow D.D., Damon-Powell T., Miesbach D. 2011. Occurrence of steroid hormones and antibiotics in shallow groundwater impacted by livestock waste control facilities. J. Contaminant Hydrol., 123: 94-103.

[36] Balcı B., Keskinkan O., Erkuş A. 2012. Atıksulardan Parasetamol Gideriminde Aktif Çamur Kullanılması. Çukurova Üniversitesi Mühendislik Mimarlık Fakültesi Dergisi, 27: 1-12.

[37] Erkuş A., Başıüyük M., Erkuş F. Ş. 2015. The examination of paracetamol and diclofenac removal in activated sludge systems under different operating conditions. International Journal of Ecosystems and Ecology Science-IJEES, 5: 315-320.

[38] Urase T., Kikuta T., 2005. Separate estimation of adsorption and degradation of pharmaceutical substances and estrogens in the activated sludge process. Water Res. 39: 1289-1300.

[39] Kone M., Cologgi D.L., Lu W., Smith D.W., Ulrich A.C. 2013. Pharmaceuticals in Canadian Sewage treatment plant effluents and surface waters: occurrence and environmental risk assessment. Environ. Technol. Rev., 2: 17-27.

[40] Sim W.J., Kim H.Y., Choi S.D., Kwon J.-H., Oh J.E. 2013. Evaluation of pharmaceuticals and personal care products with emphasis on anthelmintics in human sanitary waste, sewage, hospital wastewater, livestock wastewater and receiving water. J. Hazard. Mat., 248-249: 219-227.

[41] Fisher P.M.J., Scott R. 2008. Evaluating and controlling pharmaceutical emissions from dairyfarms: a critical first step in developing a preventative management approach. J. Cleaner Product., 16: 1437-1446.

[42] Kolodziej E., Harter T., Sedlak D.L. 2004. Dairy Wastewater, Aquaculture and Spawning Fish as Sources of Steroid Hormones in the Aquatic Environment. Environ. Sci. Technol., 38: 63776384.

[43] Fabio K., Shlomo E.B. 2016. The Occurrence of Veterinary Pharmaceuticals in the Environment: A Review. Current Analytical Chemistry, 12: 169-182.

[44] Lim S.J., Seo C.K., Kim T.H., Myung S.W. 2013. Occurrence and ecological hazard assessment of selected veterinary medicines in livestock wastewater treatment plants. J. Environ. Sci. Health Part B., 48: 658-670.

[45] Yuan Q., Snow D.D., Bartelt-Hunt S.N. 2013. Potential water quality impacts originating from land burial of cattle carcasses. Sci. Total Environ., 456-457, 246-253.

[46] Garcia-galan M.J., Garrido T., Fraile J., Ginebreda A., Diazcruz M.S. 2010. Simultaneous occurrence of nitrates and sulfonamide antibiotics in two groundwater bodies of Catalonia [Spain]. J. Hydrol., 383: 93-101.

[47] Batt A.L., Snow D.D., Aga D.S. 2006. Occurrence of sulfonamide antimicrobials in private water wells in Washington County, Idaho, USA. Chemosphere, 64:1963-1971.

[48] Matsui Y., Ozu T., Inoue T., Matsushita T. 2008. Occurrence of a veterinary antibiotic in streams in a small catchment area with livestock farms. Desalination, 226: 215-221.

[49] Kim K.R., Owens G., Kwon S.I., So K.H., Lee D.B., Ok Y.S. 2011. Occurrence and Environmental Fate of Veterinary Antibiotics in the Terrestrial Environment. Water Air Soil Poll., 214: 163-174.

[50] Luo Y., Xu L., Rysz M., Wang Y., Zhang H., Alvarez P.J.J. 2011. Occurrence and Transport of Tetracycline, Sulfonamide, Quinolone and Macrolide Antibiotics in the Haihe River Basin, China. Environ. Sci. Technol., 45:1827-1833.

[51] Zrncic M., Gros M., Balbic S., Kastelan-Macan M., Barcelo D., Petrovic M. 2014. Analysis of anthelmintics in surface water by ultra high performance liquid chromatography coupled to quadrupole linear ion trap tandem mass spectrometry. Chemosphere, 99: 224-232.

[52] Bernot M.J., Smith L., Frey F.2013. Human and veterinary pharmaceutical abundance and transport in a rural central stream influenced by confined animal feeding operation [CAFOs]. Sci. Total Environ., 445-446: 219-230.

[53] Christian T., Schneider R.J., Farber H.A., Skutlarek D., Meyer M.T., Goldbach H.E.2003. Determination of antibiotic residues in Manure, Soil and Surface Waters. Acta Hydrochim. Hydrobiol, 31: 36-44.

[54] Kemper N., Farber H., Skutlarek D., Krieter J. 2008. Analysis of antibiotic residues in liquid manure and leachate of dairy farms in Northern Germany. Agr. Water Manage, 95: 1288-1292.

[55] Chevre N. 2011. Occurrence Pharmaceuticals in surface waters: Sources, behavior, ecological risk, and possible solutions. Case Study of Lake Geneva, Switzerland. WIREs Water, 1: 69-86. 
[56] Boxall A., Long C. 2005. Veterinary Medicines and the Environment. Environ. Toxicol. Chem., 4: 759-760.

[57] Kummerer K. 2010. Pharmaceuticals in the environment. Annu. Rev. Environ. Resource, 35: 57. 